\title{
Social Business Hybrids' Diversification: Effects on Socioeconomic Combined Performance
}

Luca Mongelli, Francesco Rullani, Antonino Vaccaro and Pietro Versari

Published Online: 29 Jul 2020|https://doi.org/10.5465/AMBPP.2020.17113abstract

\section{Abstract}

Existing organizational research has extensively investigated how SBHs can preserve their hybridity but has so far provided a limited understanding of the strategic choices undertaken by these kinds of organizations, for example when they diversify in different fields of intervention. Depending on their differentiated or integrated nature, this may impact differently on their combined, socio-economic, performance. In this paper we investigate the case of the integrated SBHs, where social impact and economic returns are pursued through the very same activities and processes. We take the stance coming from the complexity theory of the organization and argue that the interdependence between the social and the commercial dimensions of integrated SBHs rises the overall organizational complexity, adding up to the complexity due to diversification, hindering the combined socio-economic performance. We further advance that the same level of complexity affects also the balance between the social and the commercial components of the combined performance, implying a specific role of diversification on the capability of the $\mathrm{SBH}$ to keep its mission and avoid, or foster, its mission drift. We test these and verify predictions by using data from the ISTAT 2011 census of the "Terzo Settore", the Italian Social Sector."

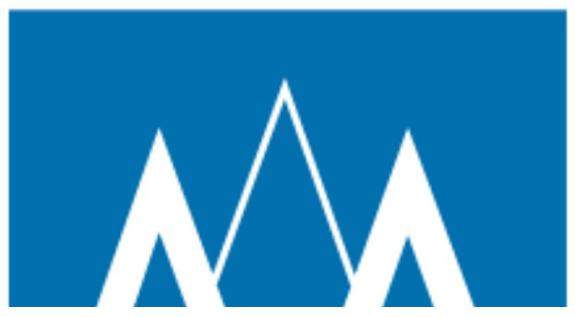



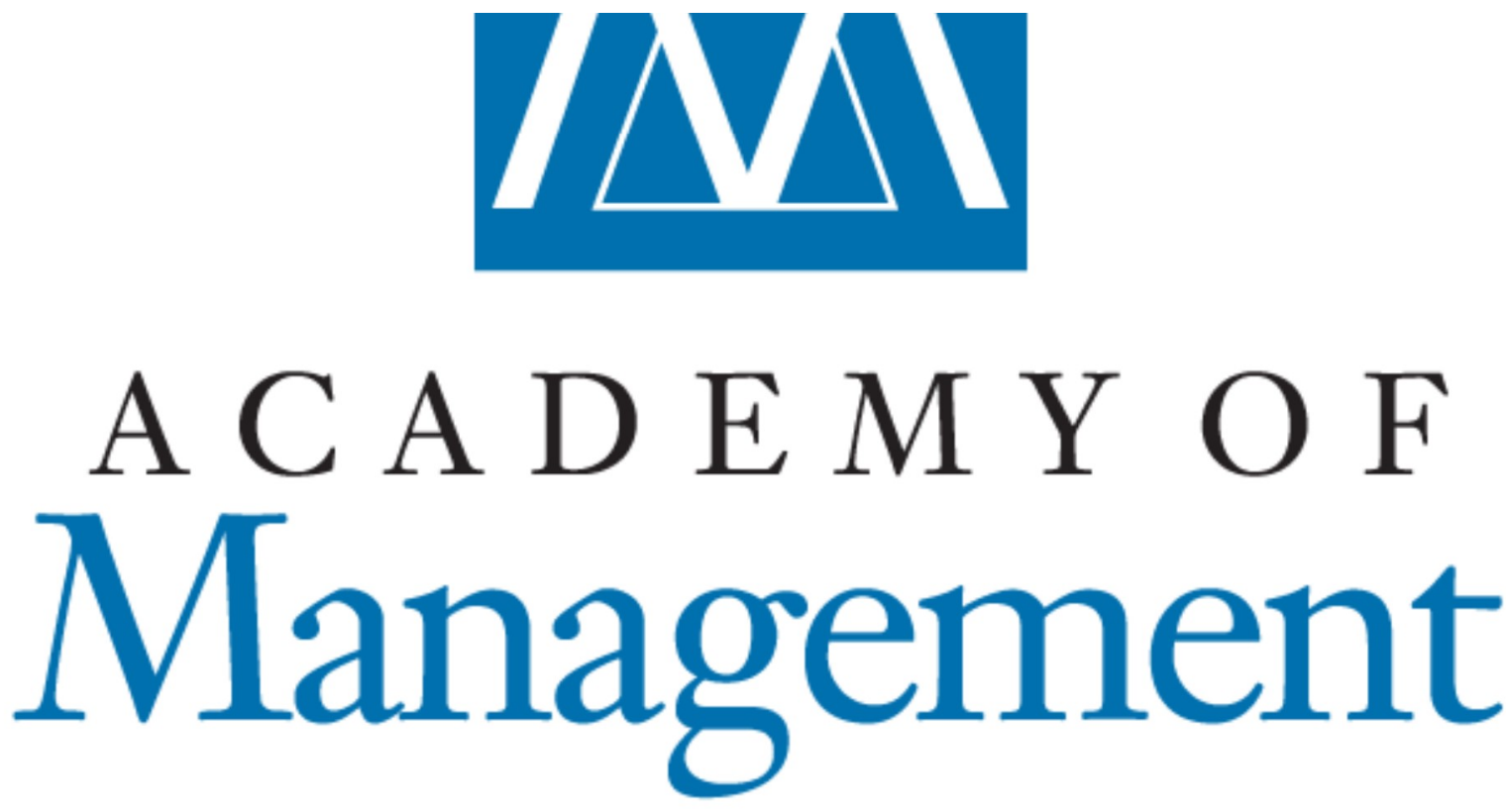

Academy of Management

555 Pleasantville Road, Suite N200

Briarcliff Manor, NY 10510-8020, USA

Phone: +1 (914) 326-1800

Fax: +1 (914) 326-1900

Privacy Policy Logo Use

(c) 2021 Academy of Management

Powered by Atypon ${ }^{\circledR}$ Literatum 